\title{
ANÁLISE DE REDES SOCIAIS E MIGRAÇÃO Dois aspectos fundamentais do "retorno"
}

\section{Dimitri Fazito}

Os sistemas empíricos de migração podem ser representados por modelos de redes sociais justamente porque existe a condição do "retorno". De um lado, tal condição essencializa o fenômeno migratório, imputando-lhe uma causa fundamental singular, isto é, a idéia original para todo migrante de que seu projeto de deslocamento só encontra sentido se o ciclo vital da migração se fecha no retorno à terra natal - um princípio simbólico que inscreve a circularidade nas migrações (Sayad, 2000).

De outro lado, este princípio simbólico do retorno também se exerce formalmente, isto é, por meio de condiçôes estruturais formais que constituem um sistema de migração. Assim, na representação formal do processo migratório, também observamos a estruturação de fluxos e pólos de origem e destino como num circuito integrado, ou

Artigo recebido em agosto/2008

Aprovado em setembro/2009 seja, operado mediante padrões relacionais das redes sociais - e, em contrapartida à essencialização, o retorno também dinamiza o processo migratório (Fazito, 2005a).

Nesse sentido, o retorno nas migrações cumpre dois aspectos básicos: 1) fundamenta simbolicamente todo e qualquer projeto migratório; 2) desempenha uma função estrutural na topologia (estruturas invariantes universais) ${ }^{1}$ de um sistema de migração que, muitas vezes, o particulariza num dado contexto (a circularidade da rede social da migração).

Este artigo pretende analisar estes dois aspectos e, principalmente, como eles atuam na qualificação de um sistema empírico de migração. Em outras palavras, a idéia defendida aqui é de que os sistemas de migração dependem do "retorno", tanto no nível dos discursos como no nível das práticas, para a consolidação de um sistema migratório estável e expansivo. 
$\mathrm{Na}$ última parte do artigo, com base na comparação topológica de quatro sistemas de migração, procura-se mostrar que o retorno desempenha, de fato, um papel estrutural elementar na organização e na evolução dos fluxos migratórios - com especial destaque para a participação dos retornados nos processos de intermediação na travessia entre origem e destino.

\section{O poder simbólico do retorno e o fenômeno migratório}

A migração é um fenômeno social e demográfico complexo, pois ao mesmo tempo em que um fluxo migratório possui características universais e estruturalmente semelhantes a outros fluxos, ele desenvolve histórica e socialmente sua singularidade (Davis, 1989).

Ao se pensar o fenômeno migratório segundo a perspectiva dos regimes demográficos poder-se-ia dizer que os deslocamentos são como eventos vitais reguladores, ou integradores das estruturas populacionais que se vinculam a uma estrutura social historicamente dada. Ao final, essa interatividade de eventos e estruturas garantiria a coerência interna de um regime demográfico específico e revelaria os padrões e impactos das migrações sobre populações e sociedades (Kreager, 1987).

$\mathrm{Na}$ migração, a unidade e a coerência entre os eventos do ciclo de vida e os significados percebidos e atribuídos ao longo de sua experiência (de indivíduos e grupos sociais) devem-se àquilo que Sayad (2000) chamou de "retorno", o elemento constitutivo da condição do migrante. No entanto, como mostra Sayad, o retorno implica um paradoxo inerente à constituição do fenômeno migratório, pois a noção mesma de retorno "está intrinsecamente circunscrita à denominação e à idéia de emigração e imigração. Não existe imigração em um lugar sem que tenha havido emigração a partir de outro lugar; não existe presença em qualquer lugar que não tenha a contrapartida de uma ausência alhures" (2000, p. 11).

O produto do fenômeno migratório, uma duplicidade da presença/ausência como faces de uma mesma moeda, não apenas unifica ele- mentos opostos em um mesmo processo (regiões expulsoras e receptoras), mas também se inscreve numa realidade política, econômica, social e historicamente distinta (Bourdieu e Wacquant, 2000).

Por exemplo, uma pessoa ou família ausente de sua terra natal e presente em outra região representa mais do que um simples deslocamento, pois, de fato, o que se opera é a transfiguração de um evento vital em um significado particular na estrutura social na qual se insere a pessoa ou grupo familiar (alteraçōes sociais profundas ocorrem tanto na origem como no destino).

Assim, para Sayad, esse deslocamento físico é também um deslocamento de poder, o poder de significação do evento na estrutura social - ou seja, o poder simbólico constitutivo do ato de migrar. Afinal,

[...] não se deixa sua terra impunemente, pois o tempo age sobre todos os seus pares. Não se prescinde impunemente do grupo e de sua ação cotidianamente presente, [...] bem como de seus mecanismos de inserção social, mecanismos que são ao mesmo tempo prescritivos e normativos e, enfim, largamente performativos (2000, p. 14).

Desse modo, podemos concluir que tal duplicidade de ausência/presença representa uma profunda ruptura na ordem do tecido social, disparada por processos populacionais reguladores.

Em Sayad, o retorno representa uma categoria fundamental do fenômeno migratório porque confere sentido e explica a unidade das relações complexas entre emigração e imigração, ausência e presença, exclusão e inserção. Além disso, o autor mostra que o retorno é uma possibilidade que só existe no seu devir, pois é em si mesmo uma justificativa manipulada politicamente pelo migrante em resposta à sua ausência. $\mathrm{O}$ retorno não é apenas um retorno ao espaço físico, mas essencialmente o retorno ao espaço social transfigurado por eventos vitais e, conseqüentemente, uma impossibilidade concreta, pois não se retorna àquela mesma estrutura de coisas e eventos que se vivia no passado e depois se "abandonou". 
O poder simbólico do retorno nasce exatamente dessa impossibilidade prática de não se poder retornar, de fato, para o mesmo "estado de coisas" que se deixou ao emigrar. Portanto, os deslocamentos não são operados apenas no espaço físico, mas sobretudo num campo de relações sociais que organiza o princípio estruturante espacial. Isto é, os deslocamentos refundam os "territórios" e suas geografias pela inserção no campo social de novos sujeitos e relações sociais (Sayad, 1998; Bourdieu, 1998).

Contudo, para que o retorno continue sendo uma boa justificativa para o emigrante e sua comunidade na defesa da racionalidade do deslocamento, tal impossibilidade prática de retorno às origens deve ser prontamente mascarada ou ignorada. Emigra-se com a crença absoluta de que um dia se retornará para o mesmo "espaço" original, como se a decisão de emigrar fosse puramente individual e pontual, localizada num espaço e tempo manipulável racionalmente.

Mais do que isto, quando o emigrante inicia sua peregrinação por outros territórios, pouco a pouco se dá conta de que a ausência no lugar de origem implica políticas extremas de negociação com os que ficaram e com aqueles estabelecidos no seu destino final. Como afirmou Bourdieu, o projeto migratório nos lança

[...] no cerne da contradição constitutiva de uma vida impossível e inevitável por via da evocação das mentiras inocentes com que se reproduzem as ilusōes sobre a terra de exílio, [e assim,] ele [Sayad] traça com pequenas pinceladas um retrato impressionante dessas "pessoas deslocadas", privadas de um lugar apropriado no espaço social e de lugar marcado nas classificaçōes sociais. Como Sócrates, o imigrante é atopos, sem lugar, deslocado, inclassificável. [...] Nem cidadão nem estrangeiro, nem totalmente do lado do Mesmo, nem totalmente do lado do Outro, o "imigrante" situa-se nesse lugar "bastardo" de que Platão também fala, a fronteira entre o ser e o nãoser social. Deslocado, no sentido de incongruente e de importuno, ele suscita embaraço (1998, pp. 11-12).
Diante da impossibilidade do retorno, muitas vezes vivida inconscientemente pelos imigrantes, parece só restar a alternativa socialmente estruturada de uma espécie de dissimulação. $\mathrm{O}$ imigrante manipula simbolicamente suas próprias experiências cotidianas ao criar suas ilusōes sobre o retorno às origens buscando, assim, justificar sua situação muitas vezes incômoda de deslocado e inclassificável.

Nesse sentido, segundo Sayad (1998) e Bourdieu (2003; Bourdieu e Wacquant, 2000) a dissimulação não é um fato planejado e pretendido pelos imigrantes (algo que pode ser também plenamente consciente mas não necessariamente), pois depende das relaçōes entre as trajetórias pessoais no contexto estrutural da migração. Os acordos tácitos sobre o reconhecimento da realidade objetiva que os cerca são feitos cotidianamente, e o migrante vai inscrevendo novos sinais (aprendizados, intuiçōes, racionalizaçôes etc.) em seu habitus (que é dinâmico e se renova sempre), e que afinal se instala em seu próprio corpo (Bourdieu, 2003).

A este respeito, vale citar nossas observaçōes de campo - em Governador Valadares e Poços de Caldas, em Minas Gerais, com migrantes brasileiros retornados que relatavam o processo de travessia ilegal da fronteira México-Estados Unidos. Os relatos sugerem que durante a travessia, como num ritual de passagem, os migrantes vão literalmente deixando as vestes do corpo ao longo do caminho, e em seu lugar vão listando as novas marcas (físicas) adquiridas e historicizadas. Chegando ao destino, essas marcas indeléveis são inscritas num novo campo social e ganham novos significados: neste caso, as marcas legitimam a condição do migrante na comunidade brasileira alhures. ${ }^{2}$

Então, a dissimulação é algo que se apreende logo quando se torna migrante, e se dissimula para si mesmo, para os outros na origem e para os outros no destino, como forma de consagrar um novo contrato social que precisa estabelecer os limites da crença social nesse triplo sentido de relações. A dissimulação engendrada pelos migrantes, em face às impossibilidades de um retorno completo, é "o efeito propriamente simbólico de desconhecimento, que resulta da ilusão [do indivíduo] da sua autonomia absoluta em relação às pressões externas" (Bourdieu, 2003, p. 212). Acredita-se livre para 
escolher o destino, o trabalho, escolher as justificativas para si mesmo sobre a ausência na origem, porque ao final acredita-se absolutamente autônomo em relação aos outros - e até a si mesmo.

Enfim, segundo Sayad,

[...] percebemos como, usando os recursos do aparelho tradicional, o informante [migrante] produz o próprio modelo do mecanismo segundo o qual se reproduz a emigração e no qual a experiência alienada e mistificada da emigração preenche uma função essencial. $\mathrm{O}$ desconhecimento coletivo da verdade objetiva da emigração [dissimulação] que todo o grupo se esforça por manter (os emigrantes que selecionam as informações que trazem quando passam algum tempo na terra; os antigos emigrantes que "encantam" as lembranças que guardaram da França; os candidatos à emigração que projetam sobre a França suas aspirações mais irrealistas etc.) constitui a mediação necessária através da qual se pode exercer a necessidade econômica (1998, p. 44).

Portanto, o retorno denuncia a natureza sistêmica e intimamente conexa do fenômeno migratório. Ainda que o retorno desejado pelos migrantes seja uma impossibilidade concreta, ele exerce uma força motriz capaz de se materializar em normas, valores e comportamentos de indivíduos e grupos. A partir da realização de um evento particular (a migração) no ciclo de vida de uma pessoa ou grupo, os significados, as relações e a inserção do imigrante na estrutura social (tanto da sociedade de origem como na de destino) são modificados, proporcionando dinâmica e complexidade a todo o sistema.

Talvez por isso as redes sociais da migração figurem como metáforas apropriadas à descrição do fenômeno migratório ao conectar ações, pessoas, objetos e categorias em um mesmo regime demográfico (Tilly, 1990). Contudo, as redes sociais que fundamentam os projetos migratórios, mais que metaforicamente, exercem de fato um constrangimento estrutural (dada a distribuição topológica das relações sociais entre os indivíduos constituintes da coletividade) que pode e deve ser mensurado (Soares, 2002; Fazito, 2005a).

\section{Análise demográfica e antropológica do retorno}

Do ponto de vista das técnicas de mensuração, tendo por foco as pesquisas feitas no Brasil (Ribeiro et al., 1998; Ribeiro e Carvalho, 1998; Carvalho, 2004), conclui-se que as migrações de retorno exercem grande impacto sobre o processo social das migrações, contribuindo definitivamente para o fortalecimento e a expansão dos fluxos migratórios.

Em linhas gerais, a análise do volume e da evolução dos contra-fluxos da migração permite-nos avaliar mais adequadamente o perfil de um sistema de migração e seu comportamento geral - com efeito, o corolário de uma tradição analítica que tem sua origem nos estudos clássicos de Ravenstein (1980; Lee, 1980).

Assim, por exemplo, as análises de Carvalho (2004) sobre os imigrantes retornados internacionais no Brasil (baseando-se nos microdados censitários do IBGE), comparando a evolução das contra-correntes migratórias entre dois períodos qüinqüenais (1986-1991 e 1995-2000), mostram que os fluxos internacionais brasileiros estão em franco processo de consolidação e expansão - notadamente os fluxos de fronteira dos brasileiros imigrantes no Paraguai e os fluxos internacionais para os Estados Unidos e Japão.

Segundo Carvalho (2004, p. 6), o volume dos retornados aumentou sensivelmente entre os dois períodos qüinqüenais, saltando de 52\% entre 1986 e 1991 para 66\% entre 1995 e 2000, o número de retornados em relação ao conjunto total de imigrantes internacionais daqueles períodos. Além disso, de todas as regiōes originárias dos contra-fluxos, aqueles provenientes do Paraguai, Estados Unidos e Japão constituíram-se nos principais centros "expulsores de retornados" (sendo os brasileiros retornados do Paraguai o contingente mais expressivo $80,7 \%$ ). ${ }^{3}$ A preponderância destes três contra-fluxos principais diz respeito à evolução dos sistemas de migração internacional do Brasil com o Paraguai, os Estados Unidos e o Japão. Após uma década de fluxos contínuos de emigrantes para esses países, as correntes migratórias de retornados atua no sentido de reforçar as redes sociais existentes e consolidar decisivamente o sistema de migração. 
O estudo de Carvalho (2004) também revela o impacto dos retornados sobre a economia nacional. Em especial a comparação dos ganhos de escolaridade e renda dos retornados internacionais vis-à-vis a população não migrante nas unidades federativas de origem. Mesmo considerando os retornados (brasileiros natos) menos favorecidos (em especial os chamados "Brasiguaios"), os diferenciais de escolaridade e renda pesam sensivelmente a favor dos imigrantes retornados (chama a atenção, nos dois qüinqüênios analisados, os retornados dos Estados Unidos e da Europa que apresentam renda quatro vezes superior aos nãomigrantes brasileiros).

Portanto, como a análise dos microdados censitários ajudam a revelar, o retorno é também um fenômeno que organiza e "justifica" os deslocamentos - no sentido das leis de Ravenstein (1980), isto é, as contracorrentes que encerram o ciclo das correntes migratórias. Desse modo, as emigraçōes internacionais, que continuam com grande ímpeto no sistema brasileiro (Carvalho et al., 2001; Carvalho, 2004), são reforçadas pelos retornados. Em geral, pela "sensação" de sucesso do empreendimento migratório, que tais retornados bemsucedidos, de certo modo, legitimam socialmente (conscientemente ou não) nas suas comunidades de origem - os dados analisados por Carvalho (2004) são evidências inequívocas do "sucesso médio" dos deslocados (renda e escolaridade).

Contudo, outros estudos sobre a migração de retorno não mostram consenso sobre a qualificação deste "sucesso" ou "fracasso" dos retornados. De fato, parece não haver qualquer consenso real sobre as causas, os padrões e os efeitos do retorno (Sayad, 2000; Sáenz e Davila, 1992; Muschkin, 1993; Lorenzo-Hernandéz, 1999; Lockwood, 1990; Cunha, 2000; Amaral e Nogueira, 1992; Scott, 1986; Gmelch, 1980; Brettell, 2000). Em linhas gerais, talvez possamos dizer que o retorno não ocorre pura e simplesmente por um "sucesso" ou um "fracasso" econômico no mercado de trabalho do destino.

Contrariamente às generalizaçōes de Ravenstein (1980), há quem diga que não se pode tratar as migraçôes fora de seu contexto histórico e social, e, nisto, descobre-se que há uma diversidade muito grande sobre as estratégias dos migrantes e seus projetos de deslocamento (Davis, 1989; Sayad, 1998).

Quanto a tais estratégias, talvez as maiores recorrências ou padrões sejam mesmo a participação das redes familiares nos deslocamentos, tanto para justificar o retorno, como a própria migração. Portanto, importante fator de determinação dos fluxos migratórios, devem ser as modificaçôes estruturais na reprodução da organização familiar em todo o processo de migração/retorno (Boyd, 1989; Tilly, 1990).

Em outro trabalho (Fazito, 2005b), constatouse que as famílias, e os retornados, desempenham papel estrutural semelhante (quando não integralmente compartilhados e interdependentes) com relação à sustentação das redes de apoio social dos migrantes e também no processo de intermediação (travessia) entre origem e destino. ${ }^{4}$

Outro ponto interessante revelado pelos trabalhos antropológicos (Gmelch, 1980; Lockwood, 1990; Margolis, 1994; Sayad, 1998; Fígoli e Vilela, 2004; Brettell, 2000) é a idéia de uma espécie de ritual de passagem para os migrantes. Isto é, em contextos específicos, onde as migraçōes se tornam estratégias sociais integradas e multiplicadoras na comunidade local (ou mesmo nacional), desenvolve-se aquilo que se tem chamado de "cultura migratória". Os deslocamentos inserem-se, desse modo, em uma matriz cultural que os legitima e lhes confere autonomia a ponto de cada projeto migratório não depender, necessariamente, de um "sucesso econômico" convencional.

Assim, as migrações legitimam-se socialmente por normas e valores próprios das comunidades, e os deslocamentos passam a significar o processo de reconhecimento e pertencimento coletivo. Em outras palavras, em comunidades como a de Governador Valadares (Soares, 2002), as estratégias sociais de negociação e construção das identidades necessariamente passam pela organização de uma cultura migratória que valoriza o ato de migrar como requisito essencial ao ser valadarense. Por conseqüência, para o jovem de Governador Valadares, emigrar para os Estados Unidos passa a ser um fato natural, o devir existencial que marca sua identidade singular - e nesse sentido, antropologicamente, o des- 
locamento passa a ser entendido como instituição social expressa ritualmente.

Então o retorno é visto como uma decorrência necessária do projeto migratório, isto é, conseqüência deste ritual de passagem, $\mathrm{o}$ ato original de emigrar que o retorno finaliza e consagra. De fato, o retorno pode então ser compreendido como fato social total (no sentido original de Mauss, 2003), catalisador do poder simbólico por meio de uma prática de sacralização do deslocamento, então ritualmente encenado e encerrado nas relaçóes comunitárias (Sayad, 1998, 2000).

Pensando a migração internacional, parece interessante conservar esta idéia de ritual de passagem, especialmente naquelas situaçóes em que os migrantes não têm necessidade evidente de emigrar por causas econômicas ou profissionais, ou em que parece haver uma "cultura migratória" singular que qualifica e necessita de rituais específicos como medida de fortalecimento da ordem moral da comunidade (caso específico de Governador Valadares).

Por fim, as teorias sobre o capital humano parecem ter alcance limitado quando comparamos alguns estudos sobre realidades empíricas diversas (Saénz e Davila, 1992; Muschkin, 1993; LorenzoHernandéz, 1999). Em geral, constata-se que as habilidades adquiridas durante a migração, com freqüência, não parecem ser operativas na maioria dos casos estudados. De fato, a importância das habilidades adquiridas no processo migratório deveriam ser ao menos relativizadas em cada configuração social no retorno.

Como se observa em diversas situaçôes (Muschkin, 1993; Lorenzo-Hernandéz, 1999; Lockwood, 1990; DeBiaggi, 2003; Scott, 1986; Sayad, 1998), as habilidades adquiridas muitas vezes podem vir a se tornar verdadeiros obstáculos à reinserção dos retornados nas comunidades de origem e atuam também como potencializadores de conflito com os não-migrantes, até dentro da família, como no caso das relaçôes de gênero entre casais (DeBiaggi, 2003).

Assim, tanto dinheiro poupado como habilidades técnicas adquiridas não parecem cumprir papel definitivo na re-adaptação do retornado em suas comunidades de origem (em trabalhos de campo, tanto em Governador Valadares como em
Poços de Caldas, observamos alguns retornados bem-sucedidos empresarialmente que, paradoxalmente, comentavam sobre a reemigração de outros tantos conhecidos que voltaram dos Estados Unidos com dinheiro e perderam tudo em maus negócios no Brasil. Como disse um retornado, talvez o maior problema para os brasileiros que têm a experiência migratória seja a dificuldade de aceitar o trabalho assalariado no Brasil. Depois que retorna, o brasileiro "não aceita mais trabalhar de empregado").

\section{Configuração estrutural das redes sociais de migração}

Esta última parte procura integrar as considerações precedentes tendo como base uma análise estrutural das topologias de quatro sistemas de migração. ${ }^{5}$ A principal questão a ser demonstrada pelas comparaçōes formais dos sistemas migratórios diz respeito às funçôes estruturais desempenhadas pelos retornados no processo social da migração ou, em outros termos, explicar objetivamente o papel (na estrutura reticular) exercido pelos retornados no sistema de migração.

Os retornados (tanto quanto os arranjos familiares, Fazito, 2005b) ocupam posiçōes estruturais fundamentais para a organização e a sustentação dos sistemas de migração, em especial, posiçôes estruturais de intermediação dos fluxos entre origem e destino. Na Figura 1, podemos visualizar a topologia de quatro sistemas de migração (analisados em maior detalhe, em Fazito, 2005a).

Cada sociograma representa um sistema empírico de migração, numa perspectiva sincrônica, abstraídos em suas topologias particulares (os vértices representam posiçôes estruturais, e os arcos direcionados representam as conexóes ou fluxos entre os vértices). Na perspectiva da Análise de Redes Sociais (ARS), é importante diferenciar posições estruturais de atores sociais. Ou seja, as posições são relacionais e se qualificam a partir das conexōes e das interdependências com outras posiçôes. Os atores ocupam concretamente uma dada posição no sistema. Com relação aos arcos, aqui eles representam o "repasse" ou fluxo de pessoas, portanto as setas indicam a 
orientação dos fluxos, por exemplo, de um vértice de origem para um vértice de destino.

Em todos estes casos analisados a posição de intermediação ocupada pelos retornados é fundamental, pois todos eles interferem direta ou indiretamente no processo de travessia dos migrantes embora nenhum destes vértices que representam a posição estrutural de intermediação ocupada pelo retornado seja formalmente "vértices-obstáculos" (isto é, cutpoints do sistema, ver Fazito, 2005a).

A definição formal de "vértice-obstáculo" implica a quebra de qualquer grafo (sistema) em pelo menos dois subcomponentes maximais. Isto é, se tais vértices forem excluídos da rede em questão, necessariamente esta ficará desconfigurada. A unificação funcional de dois ou mais vértices do grafo podem compor "blocos estruturais" que atuem, em associação, como "vértices-obstáculos", dividindo o grafo original em subcomponentes menores, como poderia ocorrer nos casos analisados a seguir (para detalhes técnicos, ver Fazito, 2005a, cap. 3; Wasserman e Faust, 1994).

Em outras palavras, os retornados tendem a ocupar posições estruturais intermediárias capazes de oferecer alternativas estratégicas ao deslocamento dos migrantes que podem tanto facilitar como dificultar o sucesso da travessia, na origem e no destino. No primeiro caso, da migração internacional de brasileiros para os Estados Unidos, vemos que os retornados potencializam os fluxos, em especial de ilegais, associando-se à intermediação de agentes, falsificadores e agências de turismo. Além disso, uma vantagem estrutural do retornado é sua rede de conexões com os membros familiares nas comunidades de origem e destino. Isto é, os retornados utilizam seus laços fortes (devido à intimidade das relações sociais intrafamiliares) nas redes pessoais para recrutamento, agenciamento e suporte dos migrantes (Goza, 2003; Soares, 2002; Fazito, 2005a).

Outra particularidade deste sistema de migração se deve ao fato de os retornados terem especializado empresarialmente suas atividades de intermediação e fundado as agências de turismo (em especial na cidade de Governador Valadares) responsáveis pela organização dos fluxos ilegais para os Estados Unidos (Soares, 2002). Segundo Goza, "muitos dos donos destas agências de turismo também já haviam sido emigrantes em algum momento" (2003, p. 274).

Algo semelhante também ocorreu noutra via do sistema de migração internacional brasileiro, nomeadamente o fenômeno do deslocamento em massa dos dekasseguis para o Japão. Como se observa no sociograma da Figura 1, os retornados também ali ocupam posição de destaque e se integram fundamentalmente às famílias na origem e principalmente no destino (Japão), consolidando aquilo que pode ser identificado como um bloco estrutural de intermediários. Este bloco é imprescindível para a consumação das atividades de intermediação gerenciadas pelos agenciadores japoneses (brokers responsáveis pelo recrutamento e encaminhamento dos dekasseguis no mercado de trabalho japonês). Contudo, é importante salientar que, diferentemente do sistema migratório de valadarenses para os Estados Unidos, no caso dos dekasseguis as migraçōes são regulares (legais) e o agenciamento dos migrantes diz respeito à sua inserção no mercado de trabalho japonês, e não no processo da travessia. Portanto, os brokers, no sistema dekassegui, são agentes oficiais e legalizados que ganham força especialmente a partir dos contatos estabelecidos com as redes pessoais dos retornados.

Assim como ocorrido no caso anterior (a relação direta entre retornados e agências de turismo em Governador Valadares), também neste caso encontramos a situação na qual os retornados, devido aos laços fortes de suas redes pessoais, conseguiram ao longo do tempo mobilizar contatos pessoais na origem e no destino para além das próprias famílias e empreenderam uma atividade especializada de intermediação e suporte dos brasileiros residentes no Japão. Este é o caso da consolidação recente das chamadas empresas dekasseguis, empresas de brasileiros para brasileiros no Japão que vendem de tudo para atender ao público imigrante (Urano, 2002; Ribas, 2003; Ocada, 2003).

Mais interessante é a convergência da análise estrutural global das redes sociais com a análise das informaçōes censitárias. No caso da emigração internacional para os Estados Unidos, percebe-se que o incremento do fluxo de emigrantes e retornados ocorre nos últimos dez ou quinze anos e que, 
Figura 1

Sociogramas de Quatro Sistemas de Migração (Fazito, 2005a)

1. Brasil/Estados Unidos

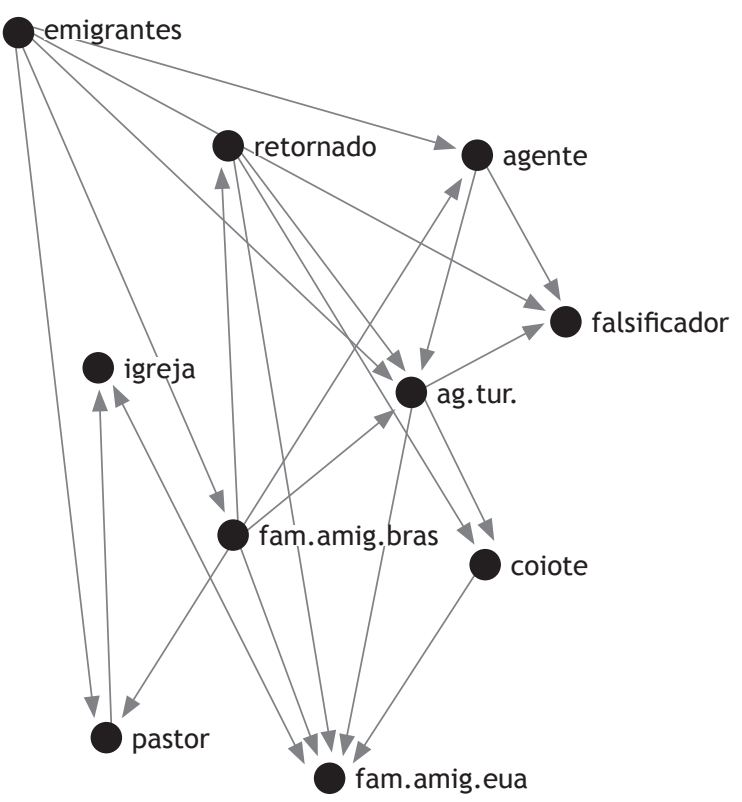

\section{Tailândia}

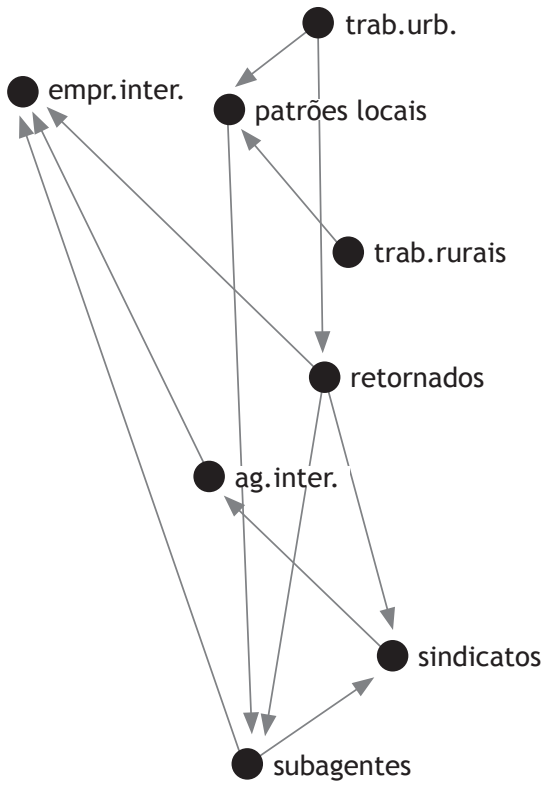

\section{Dekasseguis}

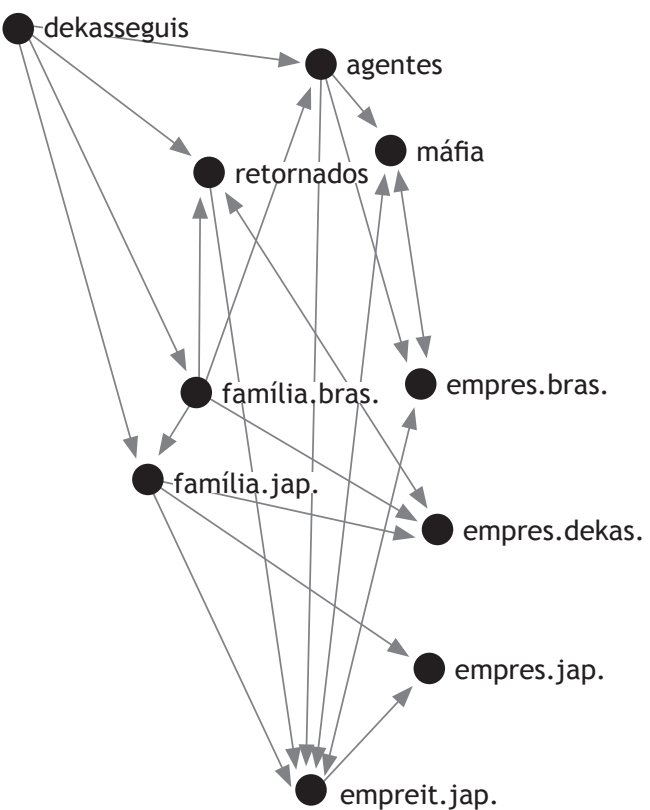

\section{Sri Lanka}

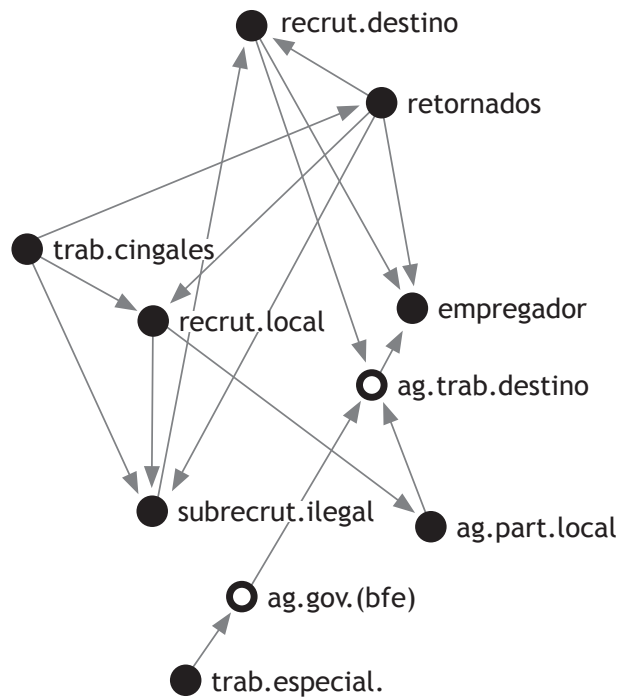


a partir deste incremento, as agências de turismo em Governador Valadares e a participação dos retornados no processo de intermediação se expandiu enormemente e se consolidou em definitivo (Soares, 2002; Fazito, 2005a; Goza, 2003).

No caso dos dekasseguis, a análise de Carvalho (2004, pp. 13-14) é contundente. Enquanto no "qüinqüênio 1986-1991, o número de migrantes provenientes do Japão era muito pequeno, 1.827 pessoas, das quais a proporção de brasileiros natos era diminuta, apenas em torno de 9\%", no período compreendido entre 1995 e 2000, o número de retornados dekasseguis chegou a $87 \%$ do fluxo de imigrantes do Japão. $\mathrm{O}$ mesmo período do estabelecimento e da expansão das empresas dekasseguis no Japão que mantêm seus laços com os retornados no Brasil (Urano, 2002; Ribas, 2003).

Por fim, os dois últimos sociogramas representam os sistemas de migração laboral entre países do Sudeste Asiático e o Oriente Médio. Ambos os grafos evidenciam as posiçôes estruturais ocupadas pelos retornados como importantes mecanismos de intermediação em todo sistema. De fato, os retornados facilitam as travessias de emigrantes ao desenvolverem conexões alternativas àquelas controladas diretamente por agentes e recrutadores.

Os retornados antecipam o recrutamento e o agenciamento dos emigrantes trabalhadores, influenciando inclusive nas etapas migratórias posteriores (também já no destino). Por intermédio de suas redes pessoais, os retornados conectam os emigrantes aos agenciadores, ou diretamente às agências de trabalho internacional, e em vários casos, até diretamente aos empregadores no destino (caso notável daquele descrito e analisado por Eleens e Speckman, 1990). Assim, prescindindo das estratégias oficiais, ou demolindo os monopólios constituídos ilegalmente pelas redes mafiosas como é o caso dos sindicatos de trabalhadores tailandeses (Singhanetra-Renard, 1992), esses retornados inseridos no contexto cultural asiático desempenham papéis sociais legitimados pela coletividade e potencializados pela configuração topológica das redes sociais da migração.

Além disso, como ficou evidenciado nos casos anteriores, nos sistemas asiáticos os autores também observaram o fenômeno recorrente de emi- grantes pioneiros terem se constituído no retorno posterior em agenciadores e recrutadores oficiais ou ilegais (Eleens e Speckman, 1990; SinghanetraRenard, 1992). Aqui se observa, por assim dizer, a convergência entre o constrangimento estrutural (dada a topologia do sistema em questão) e o constrangimento social legitimado pelo contexto cultural (que garante maior poder simbólico aos que possuem capital social elevado nas relações familiares). Contudo, é importante salientar que a convergência entre esses fatores não garante por si só a associação do migrante retornado com as redes de atravessadores das migrações (como no caso exemplar das agências de turismo em Governador Valadares). A partir da análise das redes sociais nos sistemas de migração, podemos evidenciar os aspectos estruturais que favorecem determinados atores (como é o caso especial dos retornados e dos grupos familiares) a ocuparem posiçôes sociais específicas. Porém, a ocupação e o exercício efetivos de determinados papéis estruturais, como é o caso da intermediação da migração, pode em muitos casos não se concretizar em favor de outros atores - nestes casos, muitos migrantes retornados, embora sejam "favorecidos" estruturalmente, podem não efetivar suas posiçōes.

\section{Consideraçóes finais}

As análises sobre os retornados, tal como procuramos mostrar, tanto com base em análises de caráter antropológico sobre o poder simbólico e ritual do retorno, como a partir da análise formal e estrutural das migrações, reforçam a idéia da circularidade e da expansão dos sistemas migratórios segundo padrōes relacionais específicos.

Em linhas gerais, pode-se dizer que um sistema de migração se define pela associação e sobreposição de diferentes "redes migratórias": especificamente, "redes de fluxos" e "redes sociais". Enquanto a rede de fluxos representa a estrutura topológica bruta e abstrata de um sistema, a rede social representa a topologia sensível e correspondente ao contexto histórico-social do qual faz parte.

Enfim, em se tratando de um sistema de migração, embora a rede de fluxos e a rede social se 
configurem a partir de pessoas (nós) e suas relações (laços), deve-se pensar em dimensões analíticas diversas mas complementares. A rede de fluxos referese ao agregado estatístico da população de indivíduos que se deslocam entre duas regiōes distintas (é o simples somatório dos deslocados que representam os vínculos entre duas regiōes tomadas como nós da rede). A rede social refere-se não ao agregado, mas à estrutura social composta das relaçôes sociais cotidianas entre as diversas pessoas, migrantes $\mathrm{e}$ não-migrantes, de uma dada comunidade.

Além disso, pode-se dizer que a posição de intermediação em um sistema de migração (ocupada pelos retornados), tanto quanto toda posição de intermediação em quaisquer sistemas sociais (sejam quais forem os atores sociais ocupantes de tal posição), é uma prerrogativa formal relativa que, em larga medida, independe dos processos empíricos (Fazito, 2005a). Em outras palavras, a combinação ou a sobreposição do sistema empírico com suas relações de ordem formal (topológica) pode ocorrer ou não. Porém, se tal sobreposição ocorre, então ela indica atores posicionados mais vantajosamente do que outros e, nesse sentido, empiricamente mais poderosos e monopolistas dos fluxos que outros (Barabási, 2003).

Portanto, a análise estrutural mostra que, mesmo se não existissem atores concretos capazes de ocuparem com sucesso a posição de intermediação num sistema social qualquer, cedo ou tarde outros atores poderiam conquistar esse espaço, dados os constrangimentos formais relativos da estrutura reticular (Soares, 2002; Fazito, 2005a). Pois todo sistema social, por definição, é composto (segundo sua topologia) por vértices/nós e arcos/relaçôes que se inscrevem na realidade social e obedecem a uma hierarquia social (de normas e valores) associada à hierarquia estrutural que determina a possibilidade formal de ocupação de posições, intermediárias ou não, componentes da estrutura (Knoke e Kuklinsky, 1983; Degenne e Forsé, 1999).

Desse modo, procurou-se mostrar a utilidade da Análise de Redes Sociais para os estudos das Ciências Sociais em geral, tomando-se o caso das análises demográficas e sociológicas das migraçôes.

Como conclusão, parece evidente que os retornados desempenham funções singulares e essenciais a todo o processo social da migração. Seja quanto aos aspectos simbólicos e de legitimação social dos deslocamentos, seja quanto aos aspectos operativos dos fluxos. Além disso, como ficou demonstrado, os retornados têm a função primordial de "fechar" o sistema de migração e conferir o sentido decisivo aos projetos de deslocamento, garantindo a circularidade dos movimentos populacionais e a legitimidade dos eventos nos ciclos de vida de indivíduos e grupos sociais.

\section{Notas}

1 Sobre a importância da topologia em diversos sistemas reticulares, ver especialmente Barabási (2003).

2 Numa breve incursão etnográfica, ao longo dos meses de junho e julho de 2007, tivemos a oportunidade de estudar o contexto da emigração internacional para os Estados Unidos nas cidades de Governador Valadares e Poços de Caldas (ambas em Minas Gerais). Fizemos entrevistas em profundidade com migrantes retornados dos Estados Unidos, sendo que a maioria dos entrevistados se constituía de migrantes irregulares, que entraram nos Estados Unidos através da fronteira mexicana. Também entrevistamos "emigrantes potenciais" e "agentes da migração".

3 Entretanto, é preciso salientar a especificidade do sistema de migração entre Brasil e Paraguai, no qual se insere todo o processo de formação e expansão da chamada comunidade de "Brasiguaios". Este sistema de migração, com suas peculiaridades históricas, apresenta uma dinâmica bastante particular (Marques, 2008)

4 Este ponto será mais bem desenvolvido na próxima seção pela análise formal das topologias de quatro sistemas empíricos de migração.

5 Para mais detalhes sobre os aspectos metodológicos e conceituais da Teoria dos Grafos e Análise de Redes Sociais utilizadas como suporte destas análises, ver Fazito (2005a).

\section{BIBLIOGRAFIA}

AMARAL, Ana Elizabeth e NOGUEIRA, Ronidalva. (1992), "A volta da asa branca e as impressões do retorno". Anais do Encontro da 
Associação Brasileira de Estudos Populacionais, Caxambu, MG.

BARABÁSI, Albert-László. (2003), Linked: how everything is connected to everything else and what is means for business, science and everyday life. $1^{\text {a }}$ edição. Nova York, Plume Book.

BOURDIEU, Pierre. (1998), "Um analista do inconsciente", in Abdelmalek Sayad, A imigração ou os paradoxos da alteridade (Prefácio). $1^{\mathrm{a}}$. edição. São Paulo, Edusp, pp. 9-12.

. (2003), O poder simbólico. 6.ed. São

Paulo, Bertrand Brasil.

BOURDIEU, Pierre\& WACQUANT, Loïc. (2000), "The organic ethnologist of Algerian migration". Ethnography, 1 (2): 173-182.

BOYD, Monica. (1989), "Family and personal networks in international migration: recent developments and new agendas". International Migration Review, 23 (3): 638-670.

BRETELL, Caroline. (2000), "Theorizing migration in anthropology: the social construction of networks, identities, communities and globalscapes", in Caroline Brettell e James Frank Hollifield, Migration theory: talking across disciplines, Nova York, Routledge, pp. 97-135.

CARVALHO, José Alberto M. (2004), "Migrações internacionais do Brasil nas duas últimas décadas do século XX: algumas facetas de um processo complexo, amplamente desconhecido". Trabalho apresentado no encontro sobre Remessas, Previdência Social e Políticas Públicas, Brasília-DF (mimeo.).

CARVALHO, José Alberto M. et al. (2001), "Estimativas dos saldos migratórios internacionais e do número de emigrantes internacionais das grandes regiōes do Brasil - 1986/1991 e 1991/1996”, in Mary Garcia Castro, Migraçôes internacionais: contribuiçôes para políticas, Brasília, CNPD, pp. 243-252.

CUNHA, Aparecido Soares. (2000), "Migração de retorno num contexto de crises, mudanças e novos desafios". Anais do Encontro da Associação Brasileira de Estudos Populacionais, Caxambu, MG.

DAVIS, Kinsgley. (1989), "Social science approaches to international migration", in Michael Teitelbaum e Jay Winter (eds.), Population and resources in western intellectual traditions, Cambridge, Cambridge University Press, pp. 245261.

DEBIAGGI, Sylvia. (2003), "Famílias brasileiras em um novo contexto cultural", in Ana Cristina B. Martes e Soraya Fleischer (orgs.), Fronteiras cruzadas: etnicidade, gênero e redes sociais, São Paulo, Paz e Terra, pp. 175-198.

DEGENNE, A. \& FORSÉ, M. (1999), Introducing social networks. $1^{\text {a }}$ edição. Londres, Sage.

EELENS, Frank \& SPECKMANN, J. D. (1990), "Recruitment of labor migrants in the middle east". International Migration Review, 24 (90): 297-322.

FAZITO, Dimitri. (2005a), Reflexões sobre os sistemas de migração internacional: proposta para uma análise estrutural dos mecanismos intermediários. Belo Horizonte, tese de doutorado, Centro de Desenvolvimento e Planejamento Regional, Universidade Federal de Minas Gerias (disponível on-line).

(2005b), "A configuração estrutural dos arranjos familiares nos processos migratórios: a força dos laços fortes para a intermediação". Texto submetido para avaliação e participação no seminário "As famílias e as políticas públicas no Brasil", 21-22 de novembro, Abep, Belo Horizonte.

FÍGOLI, Leonardo H .G. \& VILELA, Elaine. (2004), "Migración, identidad y multiculturalismo: sírios y libaneses en Brasil”. Trabalho apresentado no Congresso Latino Americano de Sociología da ALA, Lima, Peru (mimeo.).

GMELCH, George. (1980), "Return migration". Annual Review of Anthropology, 9: 135-153, Nova York.

GOZA, Franklin. (2003), "Redes sociais e a integração de brasileiros no Canadá e nos Estados Unidos", in Ana Cristina B. Martes e Soraya Fleischer (orgs.), Fronteiras cruzadas: etnicidade, gênero e redes sociais, São Paulo, Paz e Terra, pp. 263-288.

KNOKE, David \& KUKLINSKY, James. (1983), Network analysis. $1^{\text {a }}$ edição. Londres, Sage.

KREAGER, Philip. (1987), "Demographic regimes as cultural systems", in COLEMAN D. Coleman e R. Schofield (eds.), The state of po- 
pulation theory: forward from Malthus, Oxford, Basil Blackwell, pp. 131-155.

LEE, Everet S. (1980), "Uma teoria sobre a migração", in Hélio A. de Moura (coord.), Migração interna: textos selecionados, Fortaleza, BNB/ Etene, vol. 1, pp. 89-114.

LOCKWOOD, Victoria. (1990), “Development and return migration to rural French Polynesia”. International Migration Review, 24 (2): 347-371.

LORENZO-HERNÁNDEZ, José. (1999), “The nuyorican's dilemma: categorization of returning migrants in Puerto Rico". International Migration Review, 33 (4): 988-1013.

MARGOLIS, Maxine. (1994), Little Brazil: imigrantes brasileiros em Nova York, Campinas, Papirus.

MARQUES, Denise. (2008), "Mobilidade pendular na fronteira do Brasil e Paraguai: o estudo de caso dos brasiguaios". Projeto de Doutorado em Demografia, Belo Horizonte, Cedeplar/ UFMG (mimeo.).

MAUSS, Marcel. (2003), Sociologia e antropologia. São Paulo, Cosac e Naify.

MUSCHKIN, Clara. (1993), "Consequences of return migrant status for employment in Puerto Rico”. International Migration Review, 27 (1): 79-102.

OCADA, Fábio. (2003), “Migração e trabalho no mundo contemporâneo: uma experiência acerca da migração dekassegui". Travessia, 16 (45): 37-41, jan./abr..

RAVESNTEIN, E. G. (1980), "As leis da migração” in Hélio A. de Moura (coord.), Migração interna: textos selecionados, Fortaleza, BNB/ Etene, vol. 1, pp. 19-88.

RIBAS, Clarilton. (2003), “Dekassegui-koo: trabalhadores brasileiros no Japão”. Travessia, 15 (45): 7-22, jan./abr..

RIBEIRO, José T. L. \& CARVALHO, José A. M. (1998), "A imigração para Minas Gerais no período 1981/1991, com especial enfoque na migração de retorno". Anais Encontro da Associação Brasileira de Estudos Populacionais, Caxambu, MG.

RIBEIRO, José T. L. et al. (1998), "Efeitos demográficos da migração de retorno: uma proposta metodológica”. Anais Encontro da Associação Brasileira de Estudos Populacionais, Caxambu, MG.

SÁENZ, Rogelio \& DAVILA, Alberto. (1992), "Chicano return migration to the southwest: an integrated human capital approach". International Migration Review, 26 (4): 1.2481.266.

SAYAD, Abdelmalek. (1998), A imigração ou os paradoxos da alteridade. $1^{a}$ edição. São Paulo, Edusp.

. (2000), "O retorno: elemento constitutivo da condição do migrante”. Travessia, 13 (número especial): 7-32, jan..

SCOTT, Parry. (1986), "O retorno ao nordeste: refugo, família e reprodução". Anais Encontro $A B E P$.

SINGHANETRA-RENARD, Anchalee. (1992), "The mobilization of labour migrants in Thailand: personal links and facilitating networks", in Mary Kritz et al. (ed.), International migration systems, a global approach. $1^{\text {a }}$ edição. Oxford, Clarendon, pp. 190-204.

SOARES, Weber. (2002), Da metáfora à substância: redes sociais, redes migratórias e migração nacional e internacional em Valadares e Ipatinga. Belo Horizonte, tese de doutorado, Centro de Desenvolvimento e Planejamento Regional, Universidade Federal de Minas Gerias.

TILLY, C. (1990), "Transplanted networks", in Virginia Mclaughlin (ed.), Immigration reconsidered: history, sociology and politics, Nova York, Oxford University Press.

URANO, Edson. (2002), "Um olhar sobre o trabalhador dekassegu: processo imigratório e trabalho através da mídia étnica". Travessia, 15 (43): 26-30, maio/ago.

WASSERMAN, Stanley \& FAUST, Katherine. (1994), Social network analysis: methods and applications. $1^{\mathrm{a}}$ edição. Cambridge, Cambridge University Press. 
ANÁLISE DE REDES SOCIAIS E MIGRAÇÃO: DOIS ASPECTOS FUNDAMENTAIS DO "RETORNO"

\section{Dimitri Fazito}

Palavras-chave: Análise de Redes Sociais; Migração; "Retorno"; Circularidade; Sociologia relacional.

Os movimentos migratórios, entendidos como processos de deslocamento no espaço físico e social, de indivíduos e coletividades, encontram na condição do "retorno" seu princípio instrumental fundamental. Contudo, este princípio operativo desenvolve dois aspectos determinantes para a natureza e a viabilidade dos projetos migratórios em qualquer contexto histórico-social: o aspecto simbólico e o aspecto formal dos padróes relacionais das redes sociais. Neste trabalho, pretende-se analisar o fenômeno migratório a partir da Análise de Redes Sociais aplicada a quatro sistemas empíricos de migração como estudos de caso.
SOCIAL NETWORK ANALYSIS

AND MIGRATION: TWO

FUNDAMENTAL ASPECTS OF THE "RETURN"

Dimitri Fazito

Keywords: Migration; "Return;" Circularity; Social Network Analysis; Relational sociology.

Seen as the displacement process of individuals and collectivities in the physical and social space, migration phenomena meet in the "return" its fundamental instrumental principle. However, this operative principle develops two decisive aspects for the nature and viability of the migratory projects in any historicalsocial context: on the one side, the symbolic aspect that ascertains the "circularity" wanted in the human displacements; and on the other, the formal aspect of the social networks relational patterns that perform structurally the "circularity." In this work, we intend to analyze the migratory phenomenon starting from the Social Network Analysis (SNA) applied to four empiric systems of migration as case studies. This way, we hope to contribute to the theoretical-methodological development of the network analysis in the contemporary social sciences.
L'ANALYSE DES RÉSEAUX SOCIAUX ET DE MIGRATION : DEUX ASPECTS FONDAMENTAUX DU "RETOUR"

\section{Dimitri Fazito}

Mots-clés: Analyse des Réseaux Sociaux; Migration; "Retour"; Circularité; Sociologie relationnelle.

Les mouvements migratoires, considérés comme un processus de déplacement d'individus et de collectivités dans l'espace physique et social, retrouvent dans la condition du "retour" leur principe d'action fondamental. Ce principe opératif présente, toutefois, deux aspects décisifs pour la nature et la viabilité des projets migratoires dans n'importe quel contexte historique et social : l'aspect symbolique et l'aspect formel des modèles relationnels des réseaux sociaux. Ce travail propose l'analyse du phénomène migratoire à partir de l'Analyse de Réseaux Sociaux appliquée à quatre systèmes empiriques de migration utilisés comme études de cas. 